\title{
A contribuição da atenção domiciliar para a configuração de redes substitutivas de saúde: desinstitucionalização e transformação de práticas
}

\author{
Laura C. M. Feuerwerker ${ }^{1}$ e Emerson Elias Merhy ${ }^{1}$
}

Como citar

Feuerwerker LCM, Merhy EE. A contribuição da atenção domiciliar para a configuração de redes substitutivas de saúde: desinstitucionalização e transformação de práticas. Rev Panam Salud Publica. 2008;24(3):180-8.

RESUMO Objetivo. Identificar o estado da arte da atenção domiciliar no âmbito do sistema público de saúde no Brasil, analisar o seu potencial de inovação no sentido da integralidade e da humanização da atenção e indicar pistas para a sua ampliação.

Métodos. Sete experiências de cuidado domiciliar em cinco municípios brasileiros foram analisadas por meio de estudos de caso, com base em entrevistas com os cinco gestores municipais e os sete coordenadores dos serviços, com todos os componentes das equipes de atenção domiciliar e com os usuários e os familiares dos 27 casos selecionados. Todas as entrevistas foram gravadas e depois transcritas. Foram ainda analisados documentos produzidos pelos serviços (proposta política, relatórios de gestão, relatórios de avaliação, rotinas e protocolos de atenção), observados atendimentos (ao menos um de cada uma das equipes em todos os sete serviços) e analisados os casos traçadores.

Resultados. Foram identificados os seguintes tipos de atendimento domiciliar: cuidado paliativo, cuidado a pacientes com AIDS, cuidado a portadores de feridas e lesões de pele, acompanhamento de bebês prematuros, acompanhamento de acamados crônicos, antibioticoterapia endovenosa como complementação do tratamento para infecções agudas. São aspectos a destacar: a qualidade e a humanização da atenção, o trabalho em equipe, o desenvolvimento de vínculo e a responsabilização por parte dos trabalhadores e a participação efetiva dos cuidadores e das famílias na produção dos projetos terapêuticos.

Conclusão. As iniciativas examinadas mostraram que a atenção domiciliar é possível até em ambientes economicamente precários e que pode contribuir efetivamente para a produção de integralidade e de continuidade do cuidado, devendo ser ampliada no âmbito do sistema público de saúde.

Palavras-chave Assistência domiciliar, assistência à saúde, Brasil.

No Brasil, a transformação dos modos de organizar a atenção à saúde

\footnotetext{
Universidade Federal do Rio de Janeiro, PósGraduação em Clínica Médica, Rio de Janeiro, RJ. Enviar correspondência a Laura C. M. Feuerwerker no seguinte endereço: Alameda Fernão Car$\operatorname{dim} 317 / 71$, Jardim Paulista, CEP 014030-020, São Paulo, SP, Brasil. Fone: +55-11-3284.9958; e-mail: laura.macruz@gmail.com
}

vem sendo considerada indispensável para a consolidação do Sistema Único de Saúde (SUS) por pelo menos dois grandes motivos: em primeiro lugar, pela necessidade de qualificar o cuidado por meio de inovações produtoras de integralidade da atenção, da diversificação das tecnologias de saúde e da articulação da prática dos diferentes profissionais e esferas da assistência; em segundo lugar, pela necessidade de adotar modos mais eficientes de utilizar os escassos recursos, considerando que o modelo hegemônico de atenção à saúde - centrado em procedimentos - implica custos crescentes, particularmente em função do envelhecimento da população, da transição epidemioló- 
gica e, sobretudo, da incorporação tecnológica orientada pela lógica do mercado, não sendo capaz de responder às necessidades de saúde da população.

No SUS, "integralidade" é um conceito chave. Embora possa ser interpretada de muitas maneiras (1), neste estudo a integralidade pode ser traduzida pelo compromisso de garantir a atenção a todas as necessidades de saúde de cada brasileiro (2). No Brasil, ao menos dois tipos de estratégias vêm sendo implementados para construir a integralidade. O primeiro tipo propõe a transformação do modelo tecnoassistencial por meio da implementação maciça da saúde da família e da ampliação da ênfase sobre a promoção à saúde. $\mathrm{O}$ segundo tipo propõe a transformação da atenção tomando como centro as necessidades de saúde para a construção de linhas de cuidado que atravessem todos os níveis de atenção (básica, especializada, hospitalar e de urgência) e assegurem acesso e continuidade do cuidado.

A experimentação da primeira alternativa tem esbarrado em problemas recorrentes, tais como a persistente fragmentação do cuidado por níveis de atenção, havendo grandes dificuldades para articular cada um dos âmbitos da atenção à saúde com os demais (pela virtual impossibilidade de concretizar as relações de referência e contra-referência) (3). Além disso, apesar da tentativa de fortalecer a programação em saúde como alternativa para qualificar a atenção (4), verificase a reprodução da prática clínica de pronto-atendimento na atenção básica, em função da tensão permanente entre a oferta programada de ações de saúde e a demanda espontânea - geralmente enfrentada por meio de ações pontuais, orientadas, sobretudo, ao alívio dos sintomas agudos, sem que a oportunidade seja aproveitada para integrar os usuários em processos de acompanhamento estruturados. Tudo isso acarreta uma descontinuidade da atenção, dificuldade de adesão por parte dos usuários e impacto limitado, especialmente no controle das doenças crônicas. Existe também uma significativa restrição ao acesso à atenção especializada e aos métodos diagnósticos, além de dificuldades para efetivar o trabalho em equipe, persistindo os fenômenos da desresponsabilização em relação à saúde dos usuários como um todo e da perda da dimensão cuidadora dos atos de saúde (5). Dispositivos como o acolhimento e estratégias de suposta democratização da gestão muitas vezes se burocratizam e perdem o sentido e a potência ao longo tempo (6).

$\mathrm{Na}$ segunda alternativa, implementada em um número limitado de municípios, há uma tentativa de orientar a organização dos serviços pelas necessidades de saúde, produzindo linhas de cuidado que atravessam a atenção básica, especializada, ambulatorial e hospitalar (7-10). Nesses casos, tem sido necessário assegurar modalidades inovadoras de apoio e articulação entre trabalhadores e serviços (como o apoio matricial e a educação permanente em saúde, por exemplo) para possibilitar uma análise crítica permanente sobre o processo de trabalho, bem como a constante renovação de pactos (entre trabalhadores de uma mesma equipe e entre diferentes equipamentos de saúde) para assegurar o cuidado e a ampliação ou renovação das tecnologias envolvidas na atenção. Essas alternativas, mais ousadas e flexíveis, exigem estratégias mais complexas de gestão e implementação, que envolvem recursos relativamente escassos no sistema, particularmente quando se pensa de maneira ampla no Brasil, onde existem mais de $5500 \mathrm{mu}-$ nicípios, $70 \%$ dos quais com menos de 20 mil habitantes (11).

Por outro lado, as tentativas de racionalização do gasto em saúde muitas vezes produzem efeitos contraditórios com os princípios do SUS, já que têm levado a estratégias de focalização, de simplificação do cuidado e de instituição de mecanismos de controle que buscam retirar decisões da esfera de operação do mundo do trabalho no cuidado, sem falar dos riscos em relação à qualidade da atenção prestada (12). No Brasil, portanto, o debate sobre as estratégias de inovação do cuidado em saúde é atual e relevante.

A atenção domiciliar como extensão do hospital surgiu em 1947 no Hospital de Montefiore, no Bronx (Estados Unidos), para abreviar a alta hospita- lar. A importância da assistência domiciliar nos Estados Unidos cresceu a partir da década de 1980 com o surgimento da AIDS. A mudança do perfil epidemiológico e a necessidade de encontrar maneiras mais efetivas em termos de custo levaram à exploração da atenção domiciliar também em outros países ocidentais (13-16).

No Brasil, a primeira forma organizada de assistência domiciliar foi o Serviço de Assistência Médica Domiciliar de Urgência (SAMDU), criado em 1949. No inicio da década de 1990 , seguindo uma tendência mundial, surgiu o serviço organizado na forma de cuidado domiciliar (home care), concentrado em empresas privadas e nos grandes centros.

A história recente da crise do modelo de atenção hospitalar brasileiro tem estimulado o desenvolvimento de alternativas que contribuam para a produção da integralidade na rede de serviços de saúde. Assim, mesmo sem haver uma política formal ampla de financiamento de práticas assistenciais voltadas à desospitalização, inúmeras organizações de saúde vêm instituindo práticas baseadas na oferta de intervenções terapêuticas no interior do domicílio do usuário $(17,18)$. O tema vem sendo estudado tanto no Brasil como internacionalmente, sendo reconhecidos ao menos quatro campos de motivação para o desenvolvimento da atenção domiciliar:

- desospitalização de internações desnecessárias antes geradas pela fragilidade das redes de apoio em situações de vulnerabilidade social;

- processos de "alta precoce" para ampliar a rotatividade dos leitos hospitalares e evitar complicações advindas de internações prolongadas;

- busca de períodos maiores livres de intercorrências hospitalares em pacientes crônicos, com histórico de reinternações recorrentes; e

- cuidados paliativos em que o alívio da dor e uma boa morte são o objeto do trabalho das equipes (19).

Com o objetivo de aprofundar o conhecimento sobre as experiências de atenção domiciliar desenvolvidas no 
âmbito do SUS no Brasil e dar suporte à elaboração de uma política nacional para a área, foi realizada a pesquisa cujos resultados são apresentados neste artigo.

\section{MÉTODOS}

Foram estudadas experiências de atenção domiciliar desenvolvidas no âmbito do SUS nos municípios de Sobral (Estado do Ceará), Belo Horizonte (Estado de Minas Gerais), Rio de Janeiro (Estado do Rio de Janeiro), Marília (Estado de São Paulo) e Londrina (Estado do Paraná). Essas experiências foram selecionadas a partir de uma análise exploratória de serviços reconhecidos pelo Ministério da Saúde em todas as cinco regiões brasileiras. Foram selecionadas experiências em que se configurava a existência efetiva de atenção domiciliar sistematizada, contemplando as regiões Nordeste, Sudeste e Sul e municípios de diferentes portes. A coleta de dados ocorreu de novembro de 2005 a julho de 2006. Foram avaliadas sete iniciativas de atenção domiciliar: uma experiência de gestão federal, uma de gestão estadual, quatro de gestão municipal e uma experiência filantrópica. Três dessas experiências eram ligadas a hospitais e quatro a secretarias de saúde.

A pesquisa foi conduzida por meio de estudos de caso envolvendo, numa primeira fase, entrevistas semiestruturadas com os cinco secretários municipais de saúde e com os sete coordenadores dos serviços/experiências de atenção domiciliar, bem como a análise dos documentos de trabalho disponíveis em cada local (projeto político do serviço, protocolos, relatórios de gestão, boletins de produção e relatórios de avaliação).

Num segundo momento, construiuse com as equipes um banco de casos traçadores (20) - casos típicos que nos possibilitassem evidenciar a dinâmica do processo de trabalho de cada um dos serviços. Dependendo das características de cada serviço, foram selecionados um ou mais casos traçadores para análise. Foram analisados no total 27 casos traçadores, o que envolveu a leitura de todos os prontuários assim como entrevistas com todos os participantes das equipes e entrevistas com os usuários e os familiares de todos os casos em questão. Também foi observada ao menos uma visita domiciliar realizada por todas as equipes dos serviços estudados. Todas as entrevistas foram gravadas e transcritas. Os relatórios parciais produzidos em cada etapa da pesquisa foram apresentados e discutidos com as equipes participantes do estudo.

Foi examinado também o processo de trabalho das equipes conforme a proposta de Mehry (21), que defende a idéia de que o trabalho em saúde mobiliza ao menos três tipos de tecnologia: duras (equipamentos, medicamentos), leve-duras (conhecimentos estruturados, como clínica e epidemiologia) e leves (tecnologias relacionais que possibilitam a produção de relações intersubjetivas entre trabalhador e usuário). Dependendo do arranjo desses tipos de tecnologia, o trabalho em saúde é mais ou menos cuidador e mais ou menos efetivo. Os diferentes modelos tecnoassistenciais em saúde se diferenciam também pelas distintas ênfases no arranjo tecnológico do trabalho em saúde.

O projeto de pesquisa foi aprovado pelo Comitê de Ética em Pesquisa do Hospital Universitário Clementino Fraga Filho da Universidade Federal do Rio de Janeiro (UFRJ). Todos os entrevistados assinaram um termo de consentimento livre e esclarecido.

\section{RESULTADOS}

Com exceção do município de Sobral, em que todos os cuidados domiciliares eram responsabilidade das equipes de saúde da família, as demais experiências contavam com equipes específicas para a atenção domiciliar. Em todos os casos, eram equipes multiprofissionais, constituídas por médico, enfermeiro, fisioterapeuta, psicólogo, nutricionista, assistente social e auxiliar de enfermagem. Existiam equipes generalistas (que cuidavam de pessoas de qualquer idade em situações clínicas de restrição crônica ao leito ou que exigiam cuidados mais intensivos do que os oferecidos em ambulatório ou hospital-dia) e equipes especialistas (orientadas ao cuidado de determinadas situações patológicas, tais como AIDS, prematuridade, doenças pulmonares, feridas, cuidados paliativos em câncer).

Em todos os municípios (exceto Sobral), o serviço de atenção domiciliar havia sido criado com o objetivo de evitar ou abreviar a internação hospitalar e também de ampliar a autonomia (dos usuários e das famílias), particularmente nas situações de restrição crônica ao leito ou de uso contínuo de medicamentos ou equipamentos como concentradores de oxigênio, sondas e catéteres. Da mesma forma, em praticamente todas as experiências, o encaminhamento ao cuidado domiciliar podia ser feito pelos hospitais e prontoatendimentos e também pelas equipes de saúde da família/atenção básica, mas a decisão a respeito da admissão cabia ao serviço de atenção domiciliar. No caso dos serviços de atenção domiciliar mantidos pelos hospitais, somente os casos advindos do próprio hospital é que eram passíveis de admissão. Apesar de ser uma alternativa à internação hospitalar, em nenhuma das situações analisadas o cuidado domiciliar foi instituído em escala grande o suficiente para substituir a internação, ou seja: a demanda potencial de casos superava a capacidade de atenção das equipes existentes.

Todos os serviços estudados estão organizados há vários anos (o mais antigo, de Londrina, há 12 anos, e o mais recente, de um hospital do Rio de Janeiro, há 3 anos). Os serviços já atenderam centenas de casos, estando disponíveis para análise e consulta relatórios consolidados, boletins de produção e prontuários.

Todos os serviços contavam com rotinas e protocolos de atenção, inclusive para as situações de emergência, além de dispor de mecanismos para assegurar o contato da família com as equipes sempre que necessário, inclusive à noite e nos finais de semana. Em todos os casos, os serviços garantiam aos usuários o fornecimento de medicamentos, materiais para curativo, son- 
das, catéteres e, quando necessário, o acesso a equipamento como respiradores e aspiradores. Todo o fornecimento de materiais era feito diretamente pelas equipes às famílias, contando com o suporte de farmácia e almoxarifado das secretarias de saúde ou hospitais envolvidos. Também em todos os casos estava assegurado o acesso ao transporte e a exames laboratoriais e radiológicos conforme a necessidade.

Antes da admissão dos usuários aos serviços de atenção domiciliar, existe uma avaliação dos casos, geralmente feita em conjunto pelo enfermeiro e pelo assistente social. A avaliação envolve a análise do caso em si, do domicílio e da dinâmica familiar em relação à disposição e possibilidades de assumir o cuidado em casa. Os cuidadores geralmente são familiares, mas às vezes são amigos e vizinhos. A freqüência das visitas varia com as necessidades de cada usuário, assim como é mobilizada a participação dos diferentes profissionais que compõem as equipes. Há casos que são visitados diariamente (até mais de uma vez ao dia no caso de antibioticoterapia endovenosa), em dias alternados, semanalmente e até quinzenalmente.

Todos os serviços apresentam resultados clínicos muito positivos, bastante bem documentados. Apesar de haver propostas claras de organização em cada serviço estudado, cada equipe revelou uma dinâmica própria de funcionamento, inclusive na construção das relações da atenção domiciliar com o restante da rede de serviços. Ou seja, dependendo da configuração do "objeto" do trabalho da atenção domiciliar, identificamos diferentes modalidades de organização do cuidado, com diferentes tipos de tecnologias de cuidado em saúde sendo mobilizadas e distintas implicações para os trabalhadores. Essas diferenças são descritas a seguir.

\section{Cuidado paliativo}

Em Londrina, Estado do Paraná, existe uma equipe especializada em cuidados paliativos, havendo um trabalho sistemático para apoiar a família na decisão de manter em casa os pacientes em fase terminal. Nos demais casos, as equipes generalistas ofereciam esse tipo de cuidado. Na situação de cuidado paliativo, as equipes sabem que não têm poder para curar ou resolver os problemas das pessoas sob seus cuidados. O que eles têm a oferecer é conforto, carinho, alívio da dor e preparação para a morte - para o usuário e para sua família. Por conta disso, desenvolvem o seu trabalho e constroem suas relações desde outro lugar que não o poder conferido pelo saber técnico. Nessa equipe, a humanidade (vulnerabilidade/impotência/ mortalidade/solidariedade) dos trabalhadores está em pauta. Dedicam-se profundamente ao cuidado, defrontando-se de maneira intensa com o sofrimento. $\mathrm{O}$ conforto que oferecem ao usuário e às suas famílias é o que faz a diferença. São as equipes mais claramente atravessadas pelos valores culturais e religiosos dos indivíduos e das famílias sob os seus cuidados.

\section{Cuidado domiciliar a pacientes com AIDS}

Existem equipes específicas em Londrina (Estado do Paraná) e Belo Horizonte (Minas Gerais). As equipes de terapia domiciliar para pacientes com AIDS defrontam-se com uma situação oposta em relação àquela enfrentada pelas equipes de cuidado paliativo: se conseguirem a adesão dos usuários ao tratamento, poderão proporcionar uma perspectiva bastante significativa de melhora, de conquista de autonomia, de prolongamento significativo da vida com qualidade. Com base nessa possibilidade, dedicam-se intensamente ao trabalho, promovendo o resgate das pessoas, de suas relações com a vida, a aceitação da doença, a compreensão das perspectivas futuras, a autonomia no cuidado da própria saúde.

Tudo isso, nas equipes observadas, era acompanhado de uma abordagem clínica intensa, que, em certas situações, implicava visitas médicas diárias e esquemas terapêuticos agressivos que demandavam de duas a três visi- tas da enfermagem ao dia. Tudo era visto como válido pela possibilidade de ampliar a perspectiva de vida, inclusive defrontar-se com universos culturais e sociais complexos e polêmicos. E é justamente nesse ponto que o conjunto da equipe revela a sua potência: produzindo possibilidades de interação, superação de preconceitos, invenção de soluções e resgate de redes de solidariedade.

\section{Acompanhamento do desenvolvimento de bebês prematuros}

Este serviço é oferecido em Belo Horizonte (Estado de Minas Gerais), pelo serviço filantrópico. As equipes que acompanham recém-nascidos prematuros, geralmente em processo de ganho de peso, trabalham com grande alegria, compartilhando com as mães e as famílias cada pequena conquista, inventando soluções criativas para superar obstáculos. Trabalham com a perspectiva da vida nova (quase sempre desejada) que vinga com o apoio e a dedicação de todos, apesar das situações adversas.

\section{Acompanhamento de acamados crônicos}

Este serviço é oferecido em todos os casos estudados. As equipes que cuidam de portadores de doenças crônicas, usuários acamados há longo tempo, trabalham com diversas situações. Em algumas, há uma perspectiva de ampliação da autonomia do usuário doente; outras vezes, a perspectiva é a de construção da autonomia do cuidador em relação às equipes de saúde. Em ambas as perspectivas, o cuidado domiciliar oferece uma possibilidade maior de recuperação do que a internação hospitalar.

Há resultados muito significativos no fechamento de feridas e na recuperação motora. São em geral processos longos de acompanhamento, que demandam a participação de toda a equipe multiprofissional e a construção de estratégias inovadoras de 
cuidado, considerando os contextos materiais e familiares. Em muitos casos, toda a família passa a estar sob cuidado da equipe, e não somente o usuário acamado. As equipes têm a possibilidade de redescobrir o poder da afetividade e do carinho na recuperação da saúde; e de construir linhas de cuidado integral e compartilhado.

\section{Antibioticoterapia endovenosa para completar tratamento de infecções agudas}

Este serviço também é oferecido em todos os casos. As equipes que cuidam de pessoas com quadros infecciosos agudos - que iniciaram antibioticoterapia endovenosa no hospital e eram acompanhadas em casa por mais 7 a 10 dias para completar o esquema terapêutico - são as que têm as menores oportunidades de construir práticas inovadoras em saúde. Claramente, há uma lógica de racionalização de gastos, de diminuição da duração das internações hospitalares e de aumento da rotatividade dos leitos envolvida neste trabalho. São as equipes com maior rotatividade de casos e com menor possibilidade de construir vínculos e estratégias de cuidado, desenvolvendo um trabalho mais marcadamente instrumental, orientado pela utilização de tecnologias leve-duras e duras (21). Em geral, o auxiliar de enfermagem é o trabalhador com presença mais marcante nas casas - porque comparece diariamente para ministrar a medicação. $\mathrm{O}$ enfermeiro acompanha o trabalho, particularmente na admissão. O médico só entra em cena no domicílio quando não há evolução favorável ou se ocorrem eventos inesperados.

\section{Atenção domiciliar produzida por equipes de saúde da família}

Este é o caso de Sobral (Estado do Ceará). As equipes de saúde da família responsáveis pela atenção domiciliar enfrentam um importante grau de tensão. Apesar de sua grande dedi- cação para evitar a internação hospitalar, defrontam-se com maiores dificuldades - técnicas, por não contarem com preparo específico para certas situações; materiais, pois nem sempre a rede básica dispõe oportunamente de todos os materiais específicos requeridos em determinadas situações de atenção domiciliar; e, sobretudo, de tempo. É difícil para as equipes assegurar às famílias o cuidado requerido e simultaneamente continuar responsáveis por todas as demais famílias do território e por toda a rotina da atenção básica.

\section{Outros aspectos relevantes do cuidado domiciliar}

Em todas as situações estudadas, sempre existe uma negociação explícita entre a equipe e o cuidador. Em geral, inicialmente, as equipes fazem algumas "exigências", principalmente em relação à organização e à limpeza do ambiente. Ao mesmo tempo, essas equipes ajudam as famílias a superar as dificuldades nesse campo. Na maior parte dos casos, pode haver atenção domiciliar em qualquer tipo de domicílio, inclusive na favela. Na prática, os únicos requisitos inegociáveis são a existência de água corrente e de energia elétrica.

Nos primeiros dias de internação domiciliar, existe um processo de transferência de tecnologia, leve-dura na maioria dos casos, por parte da equipe, que ensina o cuidador a realizar diferentes tipos de manobras e procedimentos que precisarão ser efetuados diariamente - e até várias vezes ao dia — sem a presença dos profissionais. Nesse momento já se inicia uma disputa, já que o cuidador aprende e reproduz, mas também tem opinião e leva em conta, em suas decisões, não somente os aspectos técnicos, mas muitos outros elementos da vida (afetivos, culturais, religiosos, materiais), acrescentando, à sua prática, modos tecnológicos leves de produção do cuidado. As equipes que observamos eram mais ou menos flexíveis no processo de construção desses acordos: algumas compartilhavam as condutas com a família enquanto outras entravam em conflito; mas, na maior parte dos casos estudados, as equipes levavam em conta as opiniões, os valores e as necessidades trazidos pelas famílias.

Uma outra conseqüência observada da transferência do cuidado para o domicílio foi o compartilhamento de gastos. Por um lado, uma parte da possível redução de custos proporcionada pela atenção domiciliar em relação ao hospital se deve à transferência de uma parte do trabalho de cuidado para as famílias. Por outro lado, em todos os casos estudados, os serviços forneciam a maior parte dos materiais necessários ao cuidado: medicamentos, material para curativo, sondas etc. Algumas vezes, quando havia uma "falta" específica, as famílias adquiriam alguns materiais com recursos próprios. Foi observado, entretanto, um aumento dos gastos domésticos com alguns itens, como luz (particularmente quando se utilizam equipamentos como concentradores de oxigênio) e água. Isso não parecia incomodar as equipes.

$\mathrm{O}$ que incomodava muitas equipes eram as situações de carência encontradas nas casas: falta de comida, de roupa e de material de limpeza. Não eram poucas as equipes que se mobilizavam para ajudar as famílias de algum modo, por meio de articulações com a assistência social, bazares e "cotizações entre os trabalhadores"; ou seja, os trabalhadores lançavam mão de seus próprios recursos para possibilitar, entre outros, a compra de cestas básicas de alimentos, roupas, brinquedos e organizar festas. As equipes expressaram que havia uma grande diferença entre indagar a respeito das condições de moradia e de vida e estar nas casas. Ou seja, a ampliação do contato entre trabalhadores e usuários contribuiu para alargar a noção das equipes em relação "ao que seria de sua alçada" e ampliou a sua responsabilização em relação aos usuários e suas famílias. Quando era necessária a locação de algum equipamento e a família não tinha como arcar com esse 
gasto, invariavelmente as equipes negociavam empréstimos e cessões com os hospitais com os quais trabalhavam. A solidariedade parece ser um ingrediente comum na caixa de ferramentas desses trabalhadores. A invenção também, pois há muita criatividade para superar as limitações do ambiente físico.

Todos os serviços estudados dispunham de retaguarda para transporte e exames complementares. Contudo, muitos dos médicos comentaram que, apesar de haver disponibilidade, utilizavam menos exames complementares na atenção domiciliar do que em outras situações. Apreciavam positivamente o fato de, na atenção domiciliar, usarem muito mais os recursos proporcionados pelo raciocínio clínico, já que preferiam deixar os exames para as situações em que eram realmente imprescindíveis, em função do grande transtorno que a remoção implicava em muitos casos.

Em várias das situações estudadas, existia uma forte interação entre os componentes das equipes. Dependendo da família e da situação, variava o trabalhador que detinha $o$ papel privilegiado de escuta ou aquele mais indicado para abordar certas questões junto ao usuário ou ao cuidador. Foram observados diferentes mecanismos, para além das reuniões de equipe, para as trocas de impressões e a construção dos planos terapêuticos. Havia muita confiança, cumplicidade e decisões "em ato". Essa dinâmica de cooperação é produto de uma construção ativa e levava um certo tempo para se efetivar.

Empatia, simpatia, antipatia, transferência, facilidade ou dificuldade de comunicação e entendimento das diferentes lógicas em operação, capacidade de identificar e respeitar as diferenças, compartilhamento de dores, aflições, vitórias e derrotas - tudo isso fazia parte do cotidiano das equipes. Esse aspecto mostra a importância das tecnologias leves para a produção do vínculo entre trabalhadores e usuários na produção do cuidado.

A incerteza e a novidade também faziam parte do dia-a-dia das equipes.
Cada família e cada pessoa trazem consigo desafios diferentes e é preciso descobrir a melhor maneira de enfrentar as singularidades. Entretanto, essa condição pareceu encantar boa parte das equipes, que se sentiam desafiadas e estimuladas pelo inusitado e pela novidade. Outro elemento marcante foi a paixão dos trabalhadores das equipes de atenção domiciliar, que se dedicavam de maneira muito intensa, comprometendo-se muito além do que a responsabilidade técnica e formal prescreve. As falas desses trabalhadores sugerem que o trabalho desinstitucionalizado, realizado nas casas das pessoas, oferece mais liberdade de criação na condução das suas atividades (inclusive nos aspectos clínicos), permite um relacionamento direto com as pessoas (sem intermediários) e permite conhecer contextos de vida; essa vivência mobiliza a capacidade de produzir alternativas coletivas, criativas e apropriadas para o cuidado e a produção da autonomia. Entretanto, esses trabalhadores convivem com um grau inusitado de autonomia das famílias na produção compartilhada dos projetos de cuidado que são implementados.

\section{DISCUSSÃO}

Um dos requisitos da atenção domiciliar é o apoio ativo de um cuidador que se responsabilize pelo acompanhamento diuturno do usuário sob cuidado, seja esse cuidador um familiar, um vizinho, um amigo voluntário ou um cuidador contratado. Essa modalidade implica, portanto, em transferir responsabilidades, ou seja: uma parte do cuidado que institucionalmente seria realizado pela equipe de saúde passa a ser realizada pelo cuidador ou pela família. Com isso, as famílias ganham a possibilidade de "disputar" o projeto terapêutico que será instituído em cada situação.

O cuidado domiciliar à saúde é uma prática que remonta à própria existência das famílias como unidade de organização social. Inúmeras situações de dependência cronicamente assumi- das pelas famílias sequer foram, ainda, incluídas nas iniciativas de atenção domiciliar organizadas pelo sistema de saúde. O objeto "atenção domiciliar", portanto, diz respeito apenas a uma parte das práticas de cuidado domiciliar, particularmente as que implicam uma convivência entre profissionais de saúde e cuidadores familiares.

A prática ancestral de cuidados familiares, no entanto, é decisiva para a produção das tecnologias de cuidado que as famílias e os cuidadores mobilizam para o enfrentamento das situações de "atenção domiciliar" propostas pelo sistema de saúde. Ou seja, o repertório de tecnologias de cuidado ofertado pelas equipes de saúde ao proporem as iniciativas de atenção domiciliar defronta-se, na prática, com outro repertório de tecnologias e práticas de domínio das famílias.

Como a família (particularmente o cuidador) assume a principal responsabilidade na execução dos atos de cuidado no âmbito do domicílio, ela dispõe de um grau significativo de liberdade na composição das tecnologias de cuidado efetivamente utilizadas. Ou seja, existe, necessariamente, uma combinação de repertórios de tecnologias de cuidado operando no âmbito domiciliar, que é de autoria da família, particularmente do cuidador. Portanto, mesmo quando as equipes de saúde pretendem "transferir" o cuidado hospitalar para o espaço do domicílio, propondo a reprodução das práticas de assistência operadas no hospital, configura-se uma disputa de projetos terapêuticos em que as famílias têm papel definidor. Como já foi mencionado, essa ampliação da autonomia das famílias torna indispensável a negociação dos projetos terapêuticos por parte das equipes e traz para sua agenda um universo de questões, problemas e circunstâncias que ultrapassam - em muito - os aspectos biológicos das situações patológicas que se propõem sejam cuidadas no âmbito dos domicílios.

A disputa de projetos terapêuticos cria, então, um espaço de tensão que pode levar à produção de novidades no arranjo tecnológico do trabalho em 
saúde ou à captura das famílias (e das equipes) pelo projeto hegemônico de produção da atenção. Portanto, a tensão é constitutiva desse novo espaço institucional de cuidado. Essa tensão pode ser produtiva, convertendo-se em fator favorável à atenção domiciliar como espaço de "desinstitucionalização", potencialmente produtora de inovações (22). Ou pode ser uma tensão que se resolva por meio da subjugação da família e da reprodução. O projeto ético-político das equipes é decisivo na definição desse jogo.

\section{Desinstitucionalização e inovação no trabalho em saúde: dialogando com outros espaços potenciais de produção de novidade no SUS}

É interessante produzir diálogo entre o que se observa na atenção domiciliar e o que se observa em outros tipos de serviços inovadores, substitutivos ou realizados fora dos equipamentos tradicionais de saúde, tais como a saúde mental e o trabalho dos agentes.

A política de saúde mental implementada pelo SUS é uma política substitutiva, baseada na desinstitucionalização (22-26). Essa política é substitutiva porque cria mecanismos e lugares para a produção do cuidado que servem para criar alternativas à internação manicomial. A desinstitucionalização resulta da tentativa de resgatar a autonomia das pessoas em sofrimento psíquico, propiciando novos espaços para a reconstrução de sua vida. Os espaços em que se organiza o cuidado nesse caso incluem os Centros de Atenção Psicossocial (CAPS), as residências terapêuticas, os centros de convivência, as casas em geral, os abrigos, as praças e até as ruas.

É claro que esses novos equipamentos e dispositivos trazem consigo uma tensão permanente entre a reprodução do modelo manicomial e a produção de alternativas em defesa da vida e da construção da autonomia das pessoas em sofrimento psíquico, dos egressos do confinamento compulsório por toda uma vida. Existe a tensão, mas predomina a produção de novidades, sendo os resultados desse trabalho em muito superiores aos obtidos pela estratégia manicomial (27).

Outro exemplo de trabalho desinstitucionalizado ocorre na saúde da família. Dentre elementos positivos e negativos das experiências existentes, vale destacar seu elemento mais inovador, aquele que produz diferença em relação a outras modalidades de organização dessa atenção básica, que é a ação do agente comunitário de saúde.

$\mathrm{O}$ agente, necessariamente morador da área de abrangência da unidade de saúde, trabalha principalmente no "território", no espaço onde pulsa a vida, para além dos muros das unidades de saúde. Defronta-se com todos os tipos de problema que afetam o viver das pessoas e, juntamente com os usuários, toma iniciativas - individuais e coletivas - para enfrentar uma parte deles. $\mathrm{Na}$ maior parte das vezes, é dos agentes e de suas invenções que brota a alegria e o entusiasmo que chamam a atenção nos encontros das equipes de saúde da família. $\mathrm{O}$ agente é indispensável para o reconhecimento do território, de seus recursos e seus problemas. É quem produz mais fortemente a ligação entre população e unidade de saúde, apesar de, muitas vezes, sua voz não ser escutada dentro das equipes, que tentam reduzi-lo a um mero reprodutor do modelo hegemônico (28).

Agentes comunitários e equipes de saúde mental trabalham em novos territórios e são, ao mesmo tempo, alimentados e desafiados pela vida, sua complexidade, pela singularidade de cada situação. Os (novos) territórios abertos pelo trabalho realizado em espaços não institucionais parecem carregar esta potencialidade.

Assim pode ocorrer também com a atenção domiciliar. A casa, como espaço de cuidado, pode remeter a uma identificação e proximidade do cuidador para além da função técnica e da instituição hospitalar. Esses novos ingredientes, associados à maior autonomia das famílias na produção do projeto terapêutico, podem possibilitar às equipes operar na lógica da desinstitucionalização, potencializando novos lugares do cuidado, novas práticas, novas invenções no agir em saúde, novas maneiras de produzir sentidos para a vida/morte. A produção de cuidado e de novidades nas práticas de saúde seria motivada por um projeto ético-político que reconhece o usuário como sujeito, interlocutor decisivo na produção dos projetos terapêuticos (muitas vezes essa autonomia é "arrancada" pelas famílias).

Por outro lado, esse projeto ético-político tem na produção de subjetividade um elemento decisivo de mobilização dos trabalhadores. Os novos processos de subjetivação são potencializados pela ampliação da autonomia e da possibilidade do trabalho vivo em ato por parte das equipes e dos cuidadores, sendo possibilitados pelo confronto $\mathrm{CO}^{-}$ tidiano das equipes com o inusitado, com as singularidades de cada situação e com a sua própria humanidade com sofrimentos, alegrias, perdas e vitórias. Os novos processos de subjetivação são produzidos pelo resgate da solidariedade na prática profissional e pela demolição dos limites impostos pela "objetividade" da racionalidade científica à construção de relações produtivas entre trabalhadores e usuários no cuidado em saúde.

\section{Considerações finais}

A substitutividade e a desinstitucionalização são elementos fundamentais para a produção de novas maneiras de cuidar, de novas práticas de saúde em que o compromisso com a defesa da vida norteia o pacto de trabalho das equipes. Ou seja, quando a atenção domiciliar se configura como uma modalidade substitutiva de organização da atenção, como dispositivo para a produção de cuidados que efetivamente não são produzidos dentro do hospital, do ambulatório ou da instituição, ela se configura como um terreno do trabalho vivo em ato, possibilitando a produção e a invenção de práticas cuidadoras (11). 
Os CAPS, as equipes de atenção domiciliar e os agentes comunitários de saúde muitas vezes se pautam pela garantia de:

- direito de ir e vir do usuário;

- direito de o usuário desejar o cuidado;

- oferta de acolhimento na crise;

- atendimento clínico individual e coletivo dos usuários, nas suas complexas necessidades;

- construção de vínculos e referências, para eles e seus "cuidadores familiares" ou equivalentes;

- geração de alívio;
- produção de lógicas substitutivas em rede;

- matriciamento com outras complexidades do sistema de saúde; e

- geração e oferta de redes de reabilitação psicossocial inclusivas.

Quando isso ocorre, esses equipamentos e arranjos de atenção tornamse, ao mesmo tempo, dispositivos efetivos de tensão entre as novas práticas e o modelo hegemônico e entre velhos hábitos e lugares que produzem melhorias reais na construção de formas sociais de tratar e cuidar do sofrimento.
Existe grande potência nesses arranjos. A ruptura parece ser uma condição fundamental para a invenção. Mas é indispensável saber também que é preciso cuidar desses cuidadores, criar espaços de escuta e de apoio, produzir dispositivos para sua educação permanente, de modo que o inusitado, a singularidade e o desafio de se defrontar com a vida produzam implicação, compromisso e potência no agir individual e coletivo desses trabalhadores.

Agradecimentos. Estudo financiado pelo Ministério da Saúde do Brasil.

\section{REFERÊNCIAS}

1. Pinheiro R, Mattos R. Construção da integralidade: cotidiano, saberes e práticas em saúde. Rio de Janeiro: IMS ABRASCO; 2003.

2. Cecilio LCO. As necessidades de saúde como conceito estruturante na luta pela integralidade e eqüidade na atenção à saúde. Em: Pinheiro R, Mattos RA, org. Os sentidos da integralidade na atenção e no cuidado à saúde. Rio de Janeiro: IMS-UERJ-ABRASCO; 2001. Pp. 113-26.

3. Feuerwerker LCM. Modelos tecnoassistenciais, gestão e organização do trabalho em saúde: nada é indiferente no processo de luta para a consolidação do SUS. Comunic Saude Educ. 2005;9(18):489-506.

4. Schraiber LB. Programação em saúde hoje. São Paulo: Hucitec; 1990.

5. Merhy EE. Em busca da qualidade dos serviços de saúde: os serviços de porta aberta para a saúde e o modelo tecnoassistencial em defesa da vida (ou como aproveitar os ruídos do cotidiano dos serviços de saúde e colegiadamente reorganizar o processo de trabalho em busca da qualidade das ações de saúde). Em: Cecílio LC, org. Inventando a mudança na saúde. São Paulo: Hucitec; 1994. Pp. 117-60.

6. Bernardes A, Cecílio LCO, Nakao JRS, Évora YDM. Os ruídos encontrados na construção de um modelo democrático e participativo de gestão hospitalar. Cienc Saude Coletiva. 2007; 12(4):861-70.

7. Merhy EE, Magalhães JR. HM, Franco TB, Silva Bueno W. O trabalho em saúde: olhando e experenciando o SUS no cotidiano. São Paulo: Hucitec; 2003.

8. Franco TB, Peres MA de A, Foschiera MMP, Panizzi M, org. Acolher Chapecó: uma experiência de mudança do modelo assistencial. São Paulo: Hucitec; 2004.

9. Capistrano D. Da saúde e das cidades. São Paulo: Hucitec; 1995.
10. Pimenta AL. Saúde e humanização: a experiência de Chapecó. São Paulo: Hucitec; 2000.

11. Merhy EE. Saúde: cartografia do trabalho vivo. São Paulo: Hucitec; 2002.

12. Franco TB, Merhy EE. Programa de Saúde da Família (PSF): contradições de um programa destinado à mudança do modelo tecnoassistencial. Em: Merhy EE, Magalhães Jr. HM, Rimoli J, Franco TB, Bueno WS. O trabalho em saúde: olhando e experenciando o SUS no cotidiano. São Paulo: HUCITEC; 2003. Pp. 55-124.

13. Roubicek J, Salvatore A, Kavka G, Wiersba C. Servicio de internación domiciliaria para pacientes con enfermedades agudas. Rev Panam Salud Publica. 1999;6(3):172-6.

14. Segura Noguera JM, Bastida Bastús N, Martí Guadaño N, Riba Romeva M. Características y análisis de la supervivencia de las personas atendidas en el programa de atención domiciliaria del área básica de salud Raval Nord, Barcelona: 1993-2002. Rev Esp Salud Publica. 2003;77(5):581-94.

15. Agra Varela Y, Sacristán Rodea A, Pelayo Alvarez $\mathrm{M}$, Fernández J. Relación de la calidad de vida con diferentes modelos de atención domiciliaria en enfermos oncológicos terminales de un área sanitaria de Madrid. Rev Esp Salud Publica. 2003;77(5):567-79.

16. Madigan EA, Curet OL. A data mining approach in home healthcare: outcomes and service use. BMC Health Serv Res. 2006;6:18

17. Dyer P. The home health challenge: reducing acute care hospitalization. National effort aims to improve care, educate patients. J Ark Med Soc. 2005;102(4):108-9.

18. Silva KL, Sena $R$, Leite JCA, Seixas CT, Gonçalves AM. Internação domiciliar no Sistema Único de Saúde. Rev Saude Publica. 2005;39(3):391-7.

19. Fabrício SCC, Wehbe G, Nassur FB, de Andrade JI. Assistência domiciliar: a experiência de um hospital privado do interior paulista. Rev Latino-Am Enfermagem. 2004:12(5):721-6.

20. Kessner DM, Kalk CE, Singer J. Assessing health quality-the case for tracers. N Engl J Med. 1973;288(4):189-94

21. Merhy EE. A perda da dimensão cuidadora na produção da saúde: uma discussão do modelo assistencial e da intervenção no seu modo de trabalhar a assistência. Em: Campos CR, Malta DC, Reis AT, Santos AF, Merhy EE, org. Sistema Unico de Saúde em Belo Horizonte: reescrevendo o público. São Paulo: Xamã; 1998. Pp. 121-42.

22. Lancetti A. A clínica peripatética. São Paulo: Hucitec; 2007.

23. Kinoshita RT. Em busca da cidadania. Em: Campos FCB, Henriques CMP. Contra a maré à beira mar: a experiência do SUS em Santos. São Paulo: Hucitec; 1997. Pp. 67- 77.

24. Medeiros SM, Guimarães J. Cidadania e saúde mental no Brasil: contribuição ao debate. Cienc Saude Coletiva. 2002;7(3):571-9.

25. Delgado PGG, Gomes MPC, Coutinho ESF. Novos rumos na política de saúde mental. Cad Saude Publica. 2001;17(3):452-3.

26. Turdes SA, Costa NR. Cidadania e loucura: políticas de saúde mental no Brasil. Petrópolis: Vozes; 2000.

27. Merhy EE, Amaral H, orgs. A reforma psiquiátrica no cotidiano II. São Paulo: Hucitec; 2007.

28. Sousa MF. Agentes comunitários de saúde: choque de povo. São Paulo: Hucitec; 2001.

Manuscrito recebido em 8 de outubro de 2007. Aceito em versão revisada em 6 de fevereiro de 2008 . 
ABSTRACT Objective. To identify state-of-the-art home care within Brazil's public health system, evaluate its potential for improving the comprehensiveness and humanization of care, and identify areas for expanding this care modality.

Home care's Methods. Seven home care initiatives were examined and cases were analyzed

contribution to alternative health care networks: deinstitutionalization and transformation of practices through interviews with five municipal services managers, seven service coordinators, all home-care team members, and with the service recipients, as well as the family members of the 27 cases selected. All of the interviews were recorded and transcribed. We also analyzed documents created by the home care services (policy manuals, management reports, evaluation reports, and care protocols), observed each team providing care (at least once for each of the seven service types), and analyzed the selected cases.

Results. The following types of home care were identified: palliative, AIDS, skin lesions/wounds, premature infant, bedridden patient, and supplemental intravenous antibiotic therapy for acute infection. The following positive aspects should be highlighted: the quality and humanization of care, team work, the bond developed with patients and family, the sense of responsibility taken on by the health workers, and the effective participation of caretakers and families in carrying out therapy plans. Conclusion. The initiatives examined show that home care is possible even in economically disadvantaged environments and that it may effectively contribute to providing integrated and continued care. Home care should be expanded in the context of the public health system.

Key words Home nursing, delivery of health care, Brazil. 